\title{
William Crabtree's Venus transit observation
}

\author{
Nicholas Kollerstrom \\ Science and Technology Studies Department, University College London, \\ Gower Street, London WC1 E6BT, UK \\ email: nk@astro3.demon.co.uk
}

\begin{abstract}
The close collaboration between the two North-country astronomers Jeremiah Horrocks and William Crabtree gave them special insight into the new astronomy published by the recently-deceased Kepler, whereby Horrocks became the only person to apprehend that the Rudolphine tables were in fact predicting a Venus transit in 1639. This paper focuses especially upon William Crabtree's role and contribution. A comparison is made with an earlier, unsuccessful endeavour by these two concerning a possible transit of Mercury. Much of the record of their work was lost during the civil war. Finally, thanks to Christiaan Huygens, Horrock's manuscript was published by Johannes Hevelius in Danzig, in 1662.
\end{abstract}

\section{A Mercurial error}

The North-countrymen gathered round Jeremiah Horrocks comprised the beginning of the tradition of English astronomy. ${ }^{1}$ There had earlier been individuals like Thomas Hariott, who had scrutinised the Moon with his telescope, but he started no tradition, by way of others following his work. It was primarily through the work of John Flamsteed, Britain's first Astronomer Royal, that the work of this north-country group became known in Britain, as he learnt his astronomy from these people: Richard Towneley and William Gascoigne, William Crabtree and Horrocks. They drew their inspiration from the new astronomy of Kepler and combined this with a very practical approach to apparatus. According to a letter of 1640, Crabtree visited Yorkshire and saw Gascoigne's telescope 'amplified and adorned with new inventions of his own.' After describing the invention to the young Horrocks, he reported back to Gascoigne: 'My friend Mr Horrocks professeth that little touch I gave him of your inventions hath ravished his mind quite from itself and left him in exstasie between admiration and amazement.' For the period that concerns us, however, that micrometer device had not as yet been fitted to a telescope.

Horrocks revered Kepler as 'the most learned astronomer who had ever lived,' expressing the view that: 'His death was an event that must ever have happened too soon; the science of astronomy received the lamentable intelligence whilst left in the hands of a few trifling professors who had kept themselves concealed like owls until the brightness of his sun has set'2 (Kepler died in 1630, and Horrocks composed this in 1640). His Venus in Sole Visa kept breaking into verse: 'Who, mighty shade, shall sing thy praises?' he asked, although he felt at liberty to amend Kepler's newly-published Rudolphine Tables. He and his colleagues were effectively the nucleus of Keplerian astronomy in England. ${ }^{3}$

Two things had to come into the world for transits across the Sun to be discerned: the telescope, and Kepler's astronomy. The elliptical orbits of the latter enabled the planetary

1 Wilbur Applebaum, "Keplerian Astronomy after Kepler", History of Science, 34 (1996), 451-504.

2 A. Whatton, Memoir of the Life and labours of ... Horrocks 1859 (with Venus in sole Visa, pp. 109-202), p. 177.

3 I. Bernard Cohen, The Newtonian Revolution 1980, CUP, p. 229. 
nodal axes to be located in a definite manner, with their ascending and descending nodes both opposite each other and with the Sun in the middle: an instance of what Kepler meant by constructing a 'physical' astronomy. The dramatic success of Pierre Gassendi in Paris, seeing the transit of Mercury in 1631 as predicted in the Rudolphine Tables, vindicated the new Keplerian approach. The mathematics of elliptical motion was harder than that for circles, but this first-ever successful solar transit prediction convinced the cognoscenti that the effort was worthwhile. The extreme smallness of Mercury seen by Gassendi suggested that Kepler's 'solar parallax' - the angle subtended by the Earth's semi-diameter from the Sun - was too large. ${ }^{4}$ Kepler's Rudolphine Tables also predicted a Venus transit on 6 December 1631 (New Style = Gregorian Calendar), a thing equally unseen hitherto. It actually turned up on 7 December - not that this mattered, because it happened before sunrise in most of Europe. ${ }^{5}$

William Crabtree and Jeremiah Horrocks met in 1636, and an intense correspondence came to pass between them, only some of which survives - involving the devising of a new lunar theory and the Jupiter-Saturn inequality, which do not here concern us. Crabtree described Horrocks as 'my friend and second self' ${ }^{\prime}$ and posterity came to hear of Horrock's seminal work very much via Crabtree. On 29 September 1638, the 20-year-old Horrocks wrote to his 28-year-old friend Crabtree about a likely forthcoming transit of Mercury. Kepler's tables had not predicted it, giving Mercury's latitude during its forthcoming solar conjunction as nearly 18 minutes of arc. That was too wide for a transit (the Sun's angular radius we reconstruct as having then been $16^{\prime} 8^{\prime \prime}$ ), whereas other tables, Horrocks explained, were claiming it would be no more than $13^{\prime}$ or $14^{\prime}$. This inferior conjunction would happen on 21 October 1638, he wrote (Old Style = Julian Calendar), explaining that for this possible transit of Mercury with the Sun, he intended to attach his telescope to an 'oblong stick, carrying a plane surface at right angles to itself, on which to receive the Sun's image.' He drew a circle on the sheet, with numerical markings. ${ }^{7}$ He described his procedure in the same way in his Venus in sole visa. No such transit took place, with Mercury passing over the Sun at $20^{\prime}$ latitude, well outside the limit for a transit. ${ }^{8}$ Nothing comparable to the great achievement of Pierre Gassendi in Paris in 1631 took place; however, this was an important dry-run for this North-country duo, in preparation for their rendezvous with destiny over the Venus transit of 1639 - likewise not predicted by Kepler.

By way of comparison, earlier in the century Galileo had been corresponding with a colleague about how the errors of Mercury in current tables could go up to ten degrees. ${ }^{9}$ Owen Gingerich has confirmed by his reanalysis of tables of this period that such errors then existed. Mercury had far larger errors than any other planet. ${ }^{10}$ Galileo's positions for Mercury were often out by two or three degrees. Such errors of pre-Kepler tables

${ }^{4}$ Horrocks assumed that the sizes of Mercury, Venus and Earth were in proportion to their distances from the Sun, which turned out to be quite a happy conjecture: Curtis Wilson, "Horrocks, Harmonies and the Exactitude of Kepler's Third Law", 1978, in Wilson, Astronomy from Kepler to Newton Variorum, London, 1989, p. 249.

${ }^{5}$ Its last stage was visible from most of Italy and south-east Europe.

${ }^{6}$ Letter, Crabtree to Gascoigne, 7 Aug 1640 in Whatton, op. cit. (2), pp. 53-55, 54.

7 Horrocks, "The Transit of Venus across the Sun," p. 315 in Opera Posthuma, Ed. J. Wallis, 1673.

${ }^{8}$ Kindly ascertained by Bernard Yallop.

${ }^{9}$ Letter, Ottavio Brenzoni to Galileo, Padua, 19 December 1605 (No. 130, Favaro's Opere of Galileo).

10 Owen Gingerich, The Eye of Heaven, Ptolemy, Copernicus, Kepler 1993 AIP, pp. 233, 385. 
remind us of what Gingerich ascertained, that the Rudolphine Tables improved planetary positions by an entire order of magnitude. ${ }^{11}$

\section{Omitted by Kepler}

Kepler spotted the 1631 Venus transit while preparing the ephemeris for that year; however, he prepared these only up to 1636 and never got round to preparing one for 1639 - and, in consequence, failed to notice that his own Rudolphine Tables predicted a second Venus transit.

Histories hitherto have strangely averred that these tables erred in failing to predict this $^{12}$ - e.g., Dreyer: 'the Rudolphine tables threw Venus quite off the Sun's disc'; ${ }^{13}$ or, more recently, 'Kepler's tables ... predicted that Venus would just miss crossing in front of the solar disc'. ${ }^{14}$ One author has tried to argue that Kepler's unduly large solar parallax caused him to miss the event. ${ }^{15}$ In fact, the Rudolphine Tables specified a celestial latitude of $-7^{\prime} 45^{\prime \prime}$ for this Sun-Venus conjunction, ${ }^{16}$ as would have produced a transit (it was actually at $-8^{\prime} 51^{\prime \prime}$, so they erred by an arcminute), and they predicted the event nine hours early because their Venus longitude erred by half a degree. Only one person in the world appreciated the significance of this! In Horrocks' words, 'The more accurate calculations of Rudolphi very much confirmed my expectations; and I rejoiced exceedingly in the prospect of seeing Venus'. ${ }^{17}$ He requested that Crabtree look out for it. $^{18}$

\section{3. 'Rapt in contemplation'}

It dawned upon Horrocks mere weeks before the event, in October 1639, that the transit was likely. ${ }^{19}$ This short notice was his excuse for not having informed his friends: most of whom, he explained, were 'preferring their hawks and hounds, to say no worse.' He anticipated the event with 'much anxiety', because it boded bad weather: Jupiter and Mercury would be crowding together with Venus and the Sun, and from his experience he knew that this threatened bad weather. ${ }^{20}$ Especially Mercury's conjunction with the Sun 'is invariably attended with storm and tempest. ${ }^{21}$

William Crabtree's attic window of his thatched cottage at Broughton must have had a clear view of the setting Sun. The Venus transit lasted five or six hours, barely forty minutes of which were visible in the UK. It would have been fully visible in America

11 Ibid, p. 386.

12 R. Proctor, Transits of Venus 1878, p. 12: According to his [Kepler's] calculations, 'Venus passed not near enough for a transit to occur.'

13 J. Dreyer, A History of Astronomy from Thales to Kepler Dover, 1906, NY 1953, fn. p. 420.

14 D. Sellers, The Transit of Venus, Leeds 2001, p. 80

15 Eli Maor, June 82004 Venus in Transit PUP 2000: Kepler's tables showed that Venus would pass 'just below the sun's disc,' and his 'correction applied to a topocentric observer' had caused his error, pp. 32-3.

${ }^{16}$ Whatton (ref. 2) p. 180. Owen Gingerich recently (HASTRO-L, 8 July 2004) reconstructed the Rudolphine Tables as a computer program, and found that they did indicate a Venus transit. Horrocks' estimate of the Venus latitude was $-8^{\prime} 31^{\prime \prime}$ (Whatton p. 185).

17 Whatton (ref. 2) p. 111.

18 He also wrote to his brother Jonas, and asked Crabtree to inform Samuel Foster in London.

19 Allan Chapman, Three North-Country Astronomers 1982 (40 pp) p. 13.

20 Mercury, Venus, Jupiter and the Sun were all, during the transit, within five degrees of longitude.

${ }^{21}$ Whatton (ref. 2), p. 113. 
as Horrocks noted - had anyone there been capable of realising this. Its first contact started with the Sun a mere five degrees above the horizon. It was in conjunction with the descending node of Venus, giving the date of 4 December for the event (New Style), in contrast with the present ascending node Venus transit on 8 June (the Venus node axis being stationary). Not a single observatory existed in England or France, as these two prepared to view the event.

"Rap't in contemplation he stood, motionless, scarce trusting his senses, through excess of joy." This was the description given by Jeremiah Horrocks of his colleague William Crabtree, while seeing Venus move across the face of the Sun in $1639 .{ }^{22}$ The historian sees this ecstasy as the human experience of innovation: the first-ever experience, of Venus crossing the solar disc. For comparison we could describe Galileo's awe during that week when he first beheld the moons of Jupiter in 1610 - his Introduction to the Sidereus Nuncius described how the 'Maker of Stars' then spoke to him, concerning Jove and Jupiter, and his destiny. Or, the condition of Kepler when his third law of planetary motion dawned upon to him in 1618: 'it is my pleasure to yield to the inspired frenzy... ', ${ }^{23}$ he wrote. The personal experience of innovation is here recorded, at times when the world changes.

Horrocks' account rather gives the impression that William Crabtree's moment of joy caused him to miss his chance - it had been cloudy during most of the transit, and then clouds parted 'shortly before sunset':

'In a little while, the clouds again obscured the face of the Sun, so that he could observe nothing more than that Venus was certainly on the disc at the time.'

Afterwards, he made 'so rapid a sketch' of Venus as it had passed across the sun's disc. One finds this account written up in the histories. Though admitting that Crabtree was 'a person who has few superiors in mathematical learning,' the young Horrocks seems to have wished to depict his colleague as one who rather missed the time available to map the transit accurately, and so had to sketch it from memory. Did Crabtree really miss his life's biggest opportunity, leaving behind a mere sketch from memory?

Let us here recall that Crabtree had transcribed Kepler's Rudolphine Tables into a more convenient decimal notation rather than fractions ${ }^{24}$ which gives us a hint of his careful, methodical manner. The estimates then made of Venus' angular size may be compared with its true value:

\begin{tabular}{|c|c|}
\hline Horrocks & $1^{\prime} 12^{\prime \prime}$ \\
\hline Crabtree & $1^{\prime} \quad 3^{\prime \prime 25}$ \\
\hline Actual size, then & $1^{\prime} \quad 3^{\prime \prime 26}$ \\
\hline
\end{tabular}

It can never appear larger than $1^{\prime} 6^{\prime \prime}$. Crabtree's measurement was thus within a second of arc. He appears as the first astronomer to take a significant measurement having second-of-arc accuracy: for that hazy sunset, projected as a screen image of something like $20 \mathrm{~cm}$ across, was that mere fabulous good fortune?

${ }^{22}$ Whatton (ref. 2), p. 129 .

23 Johannes Kepler, Harmonices Mundi 1618, trans. by E. Aiton, A. Duncan, J. Field, The Harmony of the World Amer. Philosophical Soc. 1997, p. 391

${ }^{24}$ Whatton (ref. 2); also Allan Chapman, William Crabtree: Manchester's first Mathematician Man. Stat. Soc. 1995.

25 Whatton (ref. 2) p. 130.

26 As noted by the present writer: N. Kollerstrom, 'Crabtree's Venus transit measurement,' Quarterly Journal of the RAS, 1991, 32, 51. 


\section{Hevelius' incredulity}

The coronation of the Merry Monarch Charles II fell on 23 April 1661, the day of a Mercury transit across the Sun (3 May, New Style). The Dutchman Christiaan Huygens attended the event, during which he got to hear about a certain manuscript of Jeremiah Horrocks, together with some fragments of correspondence with Crabtree. There was, he was informed by Sir Robert Moray, no prospect of them being published in England, and might he find a publisher? ${ }^{27}$ He knew the eminent Polish astronomer Johannes Hevelius, and that he was observing this Mercury transit, so he decided to take the manuscript copy he was offered, with the intention of passing it on to the latter. ${ }^{28}$ And so it was that a manuscript composed in the North of England in 1640 Venus in Sole Visa was first published in Poland in Danzig, where Hevelius' observatory was located (nowadays called Gdansk), in 1662 - as a postscript to the latter's report on the Mercury transit. ${ }^{29}$

It was a century of dizzy change, which began with Kepler having all the stars of heaven within an "eighth sphere" a mere two German miles wide - and ended with Flamsteed estimating the size of Sirius in an infinite universe. These North-country astronomers were the first ever to apprehend the real immensity of the solar system, and they did so by keying into the notion of solar parallax: in simple language, that meant how very small Venus and Mercury looked as they journeyed across the Sun. Horrocks estimated the Sun's distance as 'at least 15,000 semi-diameters of the Earth'30 which is two-thirds of the correct value.

Kepler's third law gave the relative sizes of the planetary orbits but not their actual size, and in fact Kepler's solar system was too small by a factor of seven. Solar parallax was the key parameter indicating how far away the Sun was, and thus how large the solar system really was. In 1662, when Hevelius published Horrocks' manuscripts, he made one correction: in place of Horrock's value for the 'solar parallax' of 14 seconds of arc he made this 41 seconds of $\operatorname{arc}^{31}$ - he was unable to credit so drastic an enlargement of the solar system. ${ }^{32}$ Or, was this a mere slip of the pen on his part? ${ }^{33}$ Tycho Brahe's value for comparison had been two minutes of arc. Flamsteed in 1672 visited Richard Towneley at Burnley, and together they made a solar parallax measure of just $10^{\prime \prime}$, by using a Mars-against-the-stars method with an eyepiece micrometer (the modern value is $\left.9^{\prime \prime}\right) .{ }^{34}$ Flamsteed reported this in his first letter to the Royal Society. ${ }^{35}$

Sir Isaac Newton was not willing to believe this, and his first edition of his Principia used Hevelius' value: it cited the solar parallax as $40 "{ }^{\prime \prime}{ }^{36}$ His second edition adjusted this

27 On 11 April, Huygens had dinner at Gresham College with Robert Moray, Lord William Brouncker and others, when the publication of the Horrocks papers could have been discussed (private communication by R.H. van Gent).

28 Letters of Huygens to Hevelius (Nos 892 and 917), 21 September and 9 November 1661, in Christiaan Huygens Oeuvres Complètes The Hague 1890, vol. 3, pp. 334-335 and 385-386. This correspondence indicates that Moray had earlier received the manuscript from Paul Neile.

29 Frances Wilmoth, Ed., Flamsteed's Stars 1997, Boydell, p. 56.

30 Whatton (ref. 2), p. 151.

31 J. Hevelius, Mercurius in Sole Visus, Danzig 1662, Note to Ch. 6, p. 124.

32 Peter Aughton, The Transit of Venus, The Brief, Brilliant Life of Jeremiah Horrocks, London 2004, p. 127.

33 A year later, in a letter to Huygens, he discussed the Crabtree and Horrocks measurements, in connection with Mercury and Venus' magnitudes: Letters of Huygens (ref. 28), vol. 4 (No. 1099), pp. 308-310, 19 Feb 1663.

34 Letter of Flamsteed to Oldenburg, 16 November 1672, in: The Correspondence of John Flamsteed, First Astronomer Royal, Ed. Forbes, Murdin and Willmoth, vol. I, 1995, p. 185.

35 J. Birks, John Flamsteed, the First Astronomer Royal, 1999, p. 73.

36 Whatton (ref. 2), p. 83. 
to $10^{\prime \prime}$ - giving no credit to Flamsteed, from whom, we may assume, he obtained this key parameter. ${ }^{37}$ Newton's view of these estimates (there having been no other Venus transit since) was written up in his System of the World:

'Venus appeared to Mr Crabtrie only $1^{\prime} 3^{\prime \prime}$; to Horrox but $1^{\prime} 12^{\prime \prime}$; though by the mensurations of Hewelcke and Huygens without the sun's disc, it ought to have been seen at least $1^{\prime} 24^{\prime \prime}, 38$

Based on his understanding of solar system dimensions, he is judging his fellowcountrymen of having taken too small measurements of Venus' size. He preferred Huygens' estimate. ${ }^{39}$ It thereby became a little-appreciated fact that, in the year 1639 , a British astronomer's moment of joyful rapture did not prevent him from taking a planetary measurement accurate to a single second of arc.

\section{Acknowledgements}

I'm grateful to Wilbur Applebaum, Robert van Gent, David Sellers and Bernard Yallop for substantial assistance.

\section{Discussion}

Steve Dick: You say Newton accepted the 40" value, he knew of the other values but for some reason he chose that one. Do you know any more details on that?

Nicholas Kollerstrom: Yes, let's just quote from the third edition - Newton's final opinion in the last year of his life. Venus appeared to Mr Crabtree only $1^{\prime} 3^{\prime \prime}$; to Horrocks $1^{\prime} 12^{\prime \prime}$, though by the mensurations of Hewelcke and Huygens without the sun's disk, it ought to have been seen at least $1^{\prime} 24^{\prime \prime}$. So he's giving more weight to these European astronomers.

WALTER Brisken: It seems that if they had telescopes at that time they could have made direct visual estimates of the size of these planets. Was that not possible for some reason? Why did they rely on the transit to determine the diameters?

Nicholas Kollerstrom: Well, I think a practical astronomer should comment on this, but it was just apparently seeing the black shade against the sun that gave them the ability to tell its physical size, and I think you would need much more detailed telescopic apparatus for estimating just by looking at a planet. I don't think they had that apparatus at the time.

Allan Chapman: Just to take up on the point which you had made, Nick, about measuring very, very small objects: of course, before the development of the micrometer there was no way in which you could make an in-telescope measurement with great accuracy, and of course various people were experimenting with this; Huygens is doing it, as Cassini is doing it in France, and so on, and of course Gascoigne, who was part of the total Northern group, actually succeeds in doing it with a pair of pointers in 1640 . But that wasn't widely known until the 1660s and Robert Hooke, for instance, in the

37 Corroborated by the 9.' 5 value for solar parallax obtained by Cassini (using the 1672 observations of Mars by Richter), which he published in 1684: A. van Helden, Measuring the Universe, 1985, p. 154.

38 Isaac Newton, The Principia, Motte translation, Vol. II, UCLA Press 1963, p. 565 (His System of the World was published posthumously and its date of composition is uncertain).

39 For Huygens' obtaining of this value, see Letters of Huygens (ref. 28), 4: letter to Hevelius, 25 July 1662 (No. 1037), pp. 181-382. 
comet of 1664, tries to measure quite successfully the diameter of the nucleus of the comet by watching the comet set beyond a distant building on his skyline, where he mentions on the top of this building there was a weathercock. He notices the comet set behind the weathercock and he timed the periods, where different parts of the cometary nucleus were actually obscured by the bar of the weathercock. Then he measured subsequently the diameter of the weathercock, triangulated the distance of it from his observing post in Gresham College, so he was actually using the weathercock as a marker bar, and from this drew the conclusion that the comet's nucleus, I think, was $10^{\prime \prime}$ and its general coma about $50^{\prime \prime}$. But before the invention of the micrometer in the $1660 \mathrm{~s}$, there was no way of measuring a planet or a very, very small size in the heavens, and hence using the sun's disc was the ideal way of doing this because you could divide it into a fraction of $30^{\prime \prime}$ or $31^{\prime \prime}$.

Myles Standish: This reminds me of what people speculated with Galileo. He put on the side of his telescope something that looked like a tennis racket with cross-hatches - and he would move it back and forth until Jupiter just exactly fit one of the squares. Then he could count off the distances to the different satellites by measuring them with squares. The square effectively was a measurement of the relative diameter of Jupiter, so it's a kind of a cross-staff method.

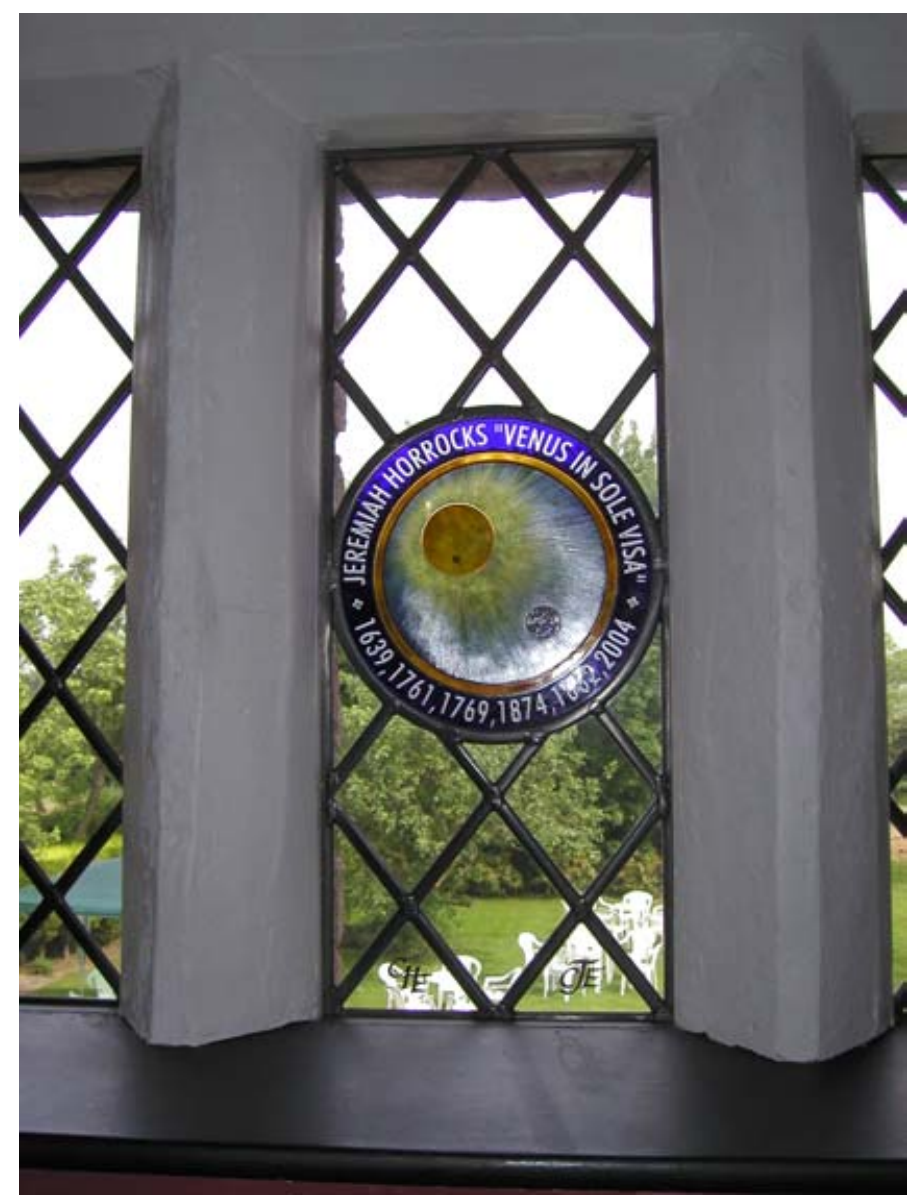

A window in Carr House, Much Hoole, Lancashire 